\title{
PARA UMA CLÍNICA DO USO DE ÁLCOOL E DROGAS COM ADOLESCENTES DAS COMUNIDADES DO RIO DE JANEIRO
}

Francisco Leonel F. Fernandes

Francisco Leonel

F. Fernandes

Professor do

Departamento

de Psicologia da

Universidade

Federal

Fluminense;

supervisor clínico-

institucional da

Erijad-Niterói/RJ.

\begin{abstract}
RESUMO: Analisando circunstâncias e elementos clínicos paradigmáticos, constata-se que as trajetórias de jovens das comunidades populares no que se refere a problemas com a Lei por uso e tráfico de drogas são, na verdade, típicas, isto é: indicam, sob eventos meramente singulares, uma produção intensa e institucionalizada desses jovens enquanto "foras da lei". Omitir esta dimensão do problema pode tornar a pesquisa científica aliada de estruturas que produzem delinquência. No entanto, uma prática derivada da clínica psicanalítica e amparada por uma reflexão sobre a institucionalidade questiona como a relação que esses adolescentes constroem com sua própria palavra nas instâncias de tratamento pode deslocar esses mecanismos institucionais.
\end{abstract}

Palavras-chave: Psicanálise, adolescentes, abordagens psicossociais, intervenção clínica, instituição.

\begin{abstract}
For a clinic of drug and alcohol abuse with adolescents from popular communities in Rio de Janeiro. Parting from clinical circumstances and paradigmatic elements, the paper argues that many of the trajectories of youngsters from popular communities facing problems with the law regarding the use and trafficking of drugs are, indeed, typical. They indicate, under mere singular events, an important and institutionalized production of these young people as outlaws. Overlooking this dimension of the problem may compromise scientific research with structures that produce delinquency. Whereas a practice oriented towards psychoanalytic clinic, informed by some reflection on the institutional framework, questions how the relation these adolescents develop, to their own word, in treatment, can change these institutional mechanisms.
\end{abstract}

Keywords: Psychoanalysis, adolescents, psychosocial approach, clinical intervention, institution. 


\section{INTRODUÇÃO}

O mal-entendido enquanto falha intrínseca de toda comunicação está presente e é estruturante das diversas práticas de intervenção psicossociais. É mesmo ele que, frequentemente, determina as possibilidades operatórias destas intervenções. O campo da saúde mental não se apresenta como exceção a essa condição. Abordaremos aqui uma dessas circunstâncias na qual ela está no cerne: a demanda de tratamento psicológico para os adolescentes das comunidades pobres, ligados ao uso e ao tráfico de drogas - demanda que envolve uma miríade de determinações e um conjunto amplo de instituições, sem falar dos determinantes econômicos e históricos mais globais.

Além disso, trata-se de uma problemática que claramente excede, por sua extensão coletiva, as possibilidades de um enquadramento psicopatológico, que situaria o indivíduo como centro ou foco, dizendo respeito muito mais a uma prática que se propagou a partir de mecanismos culturais que, nos últimos 40 anos, agiram nas fraturas das dinâmicas institucionais encarregadas de propor e zelar pela ordem, com as consequências dramáticas que conhecemos, posto serem divulgadas diariamente nas mídias. O fracasso da lei positiva e suas instituições ficam, então, evidentes.

Ora, é a partir desse real e de certo reconhecimento de que as abordagens proibicionistas e punitivas que o Direito traz são inócuas — suspeitando-se mesmo que sejam partícipes daquilo que visam combater —, que se convoca uma "tecnologia soft", como se diz — as abordagens psicossociais —, para também participar dos cenários de tratamento nas comunidades nas quais a circulação de drogas é importante. E acontece de alguns dos quadros chamados a trabalhar nessas circunstâncias, como técnicos (médicos, psicólogos, enfermeiros, assistentes sociais, etc.) serem instruídos pela psicanálise, como é o nosso caso.

Trata-se, então, para nós, de discutir o que é possível encaminhar a propósito destas situações sendo dada essa mediação da psicanálise. E isso não de forma a propor uma leitura da psicanálise ou qualquer articulação que se afirme orientada por seus conceitos de maneira muito cerrada a respeito dessa situação das drogas nas comunidades. Visamos mais a tentar expor as dificuldades que se apresentam, mais reconhecê-las servindo-nos de certa "sensibilidade" proveniente de uma prática informada pela psicanálise do que propriamente propor um entendimento psicanalítico sistemático ou interno a seus conceitos mais bem estabelecidos. Ficaremos satisfeitos se, ao final, nosso interlocutor puder nos acompanhar quanto a admitir a enorme complexidade da situação que nos solicita muito mais do que palavras de ordem simplistas que, infelizmente, têm sido correntes nos debates sobre a questão. 


\section{UM "QUASE" CASO}

Vamos iniciar com algumas indicações de um "quase caso". Trata-se, nesse uso do advérbio “quase”, de uma orientação metodológica articulada a uma manobra retórica visando a ressaltar, de saída, a complexidade da situação, justamente, em função da singularidade de alguns de seus termos. Por um lado, se trata de evitar, tanto quanto possível, propor um entendimento em que o "empírico”, as circunstâncias mesmas, apareçam como que "deduzidas" dos conceitos, “comprovando-os". Manobra que confunde o real com o sentido, e que tem como principal consequência, precisamente, evacuar o real. Por outro lado, é o caso de trazer circunstâncias que são paradigmáticas nessa problemática de forma a indicar a massa de elementos copresentes nela, produzindo-a, e que lhe dão uma opacidade na qual os níveis de determinação se embaralham, constituindo mesmo sua extrema violência. Evidenciando para nós a precariedade de nossos recursos para intervir nessa realidade, mas, ao mesmo tempo, indicando algumas direções urgentes quanto a um tratamento possível.

Nosso entendimento é o de que esse estilo de apresentação faz justiça à densidade dos fatos e é o mais justo no que diz respeito às possibilidades de apreendê-los pela via da clínica. Esperamos que isso se evidencie melhor no prosseguimento do texto. Vamos então ao "quase caso".

Digamos que seja um menor em vias de se tornar "maior", isto é, de completar seus 18 anos. Chega à unidade através do conselho tutelar ao qual foi encaminhado por alguém, por vezes os próprios parentes. Ele é uma fonte de transtornos, o que implica para a família muitas dificuldades com a comunidade e, em especial, com o tráfico, pois não é apenas ele que é ameaçado de morte por este, mas também os outros membros da família.

O ponto pivô de sua história poderia ser situado por ele mesmo, como ter presenciado ainda garoto o assassinato do irmão mais velho por seus colegas do tráfico. Sai da escola, ou "é saído", por conta da exacerbação de condutas agressivas com todos, colegas e professores. A partir daí, passa a percorrer um conjunto extenso de instituições destinadas a tratar de menores infratores. Isso porque, desde o assassinato do irmão, passou a praticar assaltos, inclusive na comunidade, culminando com sua entrada para o tráfico de drogas. É possível que em sua fala mesma apareçam relatos de participação em homicídios — não sabemos se para nos atemorizar, como é comum nesses casos. Ele percorreu quase todas as instituições de internação do estado, abrigos para menores infratores. Além disso, recebeu quase todas as medidas estipuladas por lei dirigidas a estes.

Fugiu de todas essas instituições, participou de rebeliões, etc.. Em lugar de estar cumprindo medida socioeducativa em uma delas, fugiu, digamos, foi re- 
capturado e, a partir do conselho tutelar e com o trabalho da Erijad, ${ }^{1}$ coloca-se diariamente a questão do que fazer com estes jovens, uma vez que estão em vias de completar 18 anos.

Desde 2011, esta equipe tenta fazer a mediação de situações como essa com a Justiça e com a Assistência Social para que o sujeito em questão em cada caso seja recebido também pela Saúde em um Caps AD. ${ }^{2}$

Então em nosso exemplo, ele chega a este Caps em 2013, prestes a entrar na maioridade. Um ponto marcante é que, em todo lugar que chega, rapidamente pode receber a atribuição de 'indesejável' e, como consequência, a própria instituição busca transferi-lo ou ele mesmo foge.

De fato, as instituições ficam desesperadas com a presença destes jovens. Mais recentemente, em uma delas, um jovem desenvolveu uma nova manifestação: desmaia e tem acessos de vômito. Ninguém sabe o que fazer com isso, dado que não se sabe se é fingimento ou se é um quadro orgânico grave. O mecanismo acionado pela instituição para lidar com essa situação foi, como sempre e mais uma vez, transferir o rapaz para outra instituição. Ele tem problemas com o tráfico, pois roubou os traficantes; tem problemas com a polícia, pois roubou um policial.

E é assim: as pessoas se colocam em posição de ajudá-lo e são estas justamente que, a seguir, são roubadas por ele. A mãe diz que ele é mau, é “o Mal”. Ele já tem um filho do qual vive longe. Sua atual namorada abortou anteriormente em razão de um espancamento seu e agora está grávida de novo. De seus quatro irmãos, dois foram assassinados. Um é portador de HIV, também ex-participante do tráfico, hoje religioso. O caçula é portador de necessidades especiais, por sofrer de paralisia cerebral. Este irmão religioso é o único membro da família que lhe dá algum suporte — o último foi encaminhá-lo para uma comunidade terapêutica da qual em um primeiro tempo fugiu e, após retornar a ela, por seu modo de presença, foi então expulso (usou droga lá).

A relação com a mãe, pelo vocabulário que a circunda, é muito característica: de um lado, ela é a referência de sempre, no sentido de que é para sua casa que retorna em suas fugas; por outro, é “uma puta safada; não gosta de mim”. Segundo ele, o pai é um babaca, um frouxo, "na verdade, não sou filho dele, meu pai é um vizinho com quem minha mãe teve um caso - meu pai é um corno". Quanto a seu destino, segundo suas próprias palavras é CCC, cadeia, cadeira ou

\footnotetext{
${ }^{1}$ Erijad, sigla de Equipe de Referência Infanto-juvenil de usuários de Álcool e Outras Drogas. Equipe volante que acompanha adolescentes em situação de risco referida à Saúde Mental do município de Niterói, RJ.

${ }^{2}$ Caps-AD. Abreviação de Centro de Atenção Psicossocial dedicado à usuários de Álcool e Outras Drogas. O município de Niterói tem um Caps-AD.
} 
caixão. Pelo que podemos saber, a mãe faz uso de drogas e a prostituição esteve presente em sua vida.

\section{A CULTURA E AS INSTITUIÇÕES}

Eis o "quase caso". Por que "quase"? Porque apesar das aparências, se há algo que pode singularizar esse sujeito não é cernido por essa narrativa. Na verdade, como mencionamos, esse caso é típico: temos aí muito mais um tipo do que propriamente um caso, embora seja um tipo concretizado como uma pessoa em particular, e pouco receptivo às atribuições de praxe, sempre muito gerais e comprometidas com recortes específicos dessas situações, conotando-os em um tom de "façanhas" ou peripécias sem a marca trágica que, de fato, lhe é intrínseca. Temos de falar desta forma, portanto, pela razão de que a massa de adolescentes envolvidos com a droga e o tráfico nas comunidades tem um trajeto semelhante ao esboçado. Estamos diante de uma produção institucionalizada de delinquência que na verdade é muito anterior às drogas.

Já nossos romancistas, por exemplo, Jorge Amado (1937/1972) em Capitães de areia, e até mesmo muitos relatos ainda da Primeira República, indicam essa formação, e chegam mesmo a mistificá-la na figura do "malandro”. O jornalista Sérgio Porto, o 'Stanislaw Ponte Preta’ (1966/1996; 1967/1976), um observador sarcástico da cena brasileira, fazia com todas as letras esta constatação de ser o antigo SAM, o Serviço de Atendimento aos Menores, uma escola preparatória para a delinquência, sendo o sistema penal o seu nível superior... isso ainda nos anos 1960, muito, muito antes do incremento do uso de drogas por toda a sociedade!

Esse é um primeiro ponto a considerar. Em mais de dez anos de trabalho com essa população, nunca encontramos uma história mais branda do que essa. $\mathrm{Na}$ verdade, escolhemos esse relato arbitrariamente e qualquer outro que escolhêssemos teria esses elementos. É nesse sentido que chamamos a atenção para não se tomar essas trajetórias, tão carregadas de "peripécias mortíferas", como singulares. O que é alarmante é justamente esse fato de vermos aí uma produção cultural, com a participação de instituições diversas, inclusive públicas. Começa com a família, prossegue na escola, que, após o que ocorreu com o irmão, o rejeita, mas também as outras, os abrigos, as internações diversas e a assistência social. Desde os 11 anos, ele passa por elas e o resultado é este que ele mesmo anuncia nas proximidades de seus 18 anos quanto a seu futuro: CCC, isto é, ou cadeia, ou cadeira de rodas, ou caixão. Poderiam ter sido escolhidas, também, situações em que crianças quase recém-nascidas circulam por todo tipo de instituição até chegarem à maioridade com esse mesmo destino — CCC.

Não se trata de denunciar, mais uma vez, o que todos já sabem. Há, contudo, que ressaltar alguns elementos nessa conjuntura, principalmente quando 
a psicanálise é chamada a dizer algo a seu respeito. A principal observação nesse momento é a psicanálise não fornecer álibis que justifiquem o fracasso das iniciativas públicas e que serviriam para adiar uma discussão mais consequente das conjunturas culturais que influenciam a formação de nossa juventude. Especialmente aquela oriunda das classes trabalhadoras menos abastadas, herdeiras que são da escravidão. Sobretudo, é preciso evitar algo a que muitas vezes a psicanálise inadvertidamente se presta — o psicologismo. Por exemplo, será dito ou dir-se-á desse caso que a responsabilidade recai inteiramente sobre a família, pois o fracasso desta implica necessariamente o fracasso de todas as outras instituições. Neste caso, a psicopatologia de plantão aparece preparada para propor como caso, como estrutura clínica, algo que claramente é desfecho de um processo cultural, encoberto também com a ajuda das demais ciências sociais, que também fornecem “conceitos-álibis”, por exemplo, econômicos, quando a "pobreza” é declinada como propriedade genérica funcionando quase como uma maldição, ou políticos, como a segregação da pobreza, também operada nessa mesma economia conceitual.

Tudo isso nos leva a levantar o difícil problema do que é fazer uma intervenção, clínica ou qualquer outra, que se dirija ao sujeito, que se dá no caso a caso e em função das particularidades das situações, mas que incide em pessoas que pertencem a grupos segregados e estigmatizados. Como fazer uma intervenção que abra brechas para que elas possam tomar a palavra, se responsabilizarem, sem que isso se confunda com se culpabilizarem por algo que lhes diz respeito sim, mas que concerne também à História, sendo por isso da responsabilidade da sociedade em seu conjunto — delas, inclusive.

Seguida a esta, outra consideração a se fazer gira em torno do fato de ser evidente a participação das instituições nesse resultado cultural. Temos de ir além da denúncia para alcançarmos as razões pelas quais as coisas acontecem dessa forma, pois percebermos que dizer que a delinquência acontece com a participação das instituições não quer dizer que saibamos como isso acontece. Em geral, fica-se satisfeito com a denúncia, “os governos são os responsáveis”, como se com esta atribuição "bem pensante" ficasse claro como as instituições funcionam para produzir esse resultado. A teoria geral, certo consenso, é infantil: ou seja, a de que as instituições fazem o que fazem de "propósito", tratar-se-ia de um conluio organizado contra os extratos mais vulneráveis de nossa classe trabalhadora, nosso lumpemproletariado, no sentido de marginalizá-los, de deixá-los "fora do jogo". O fato é que sucessivos governos muito bem intencionados não mudaram substantivamente a situação, nem tampouco o nível da discussão. Basta vermos a crise do sistema penitenciário e as origens da população carcerária precisamente a circunstância aqui abordada. 
Recentemente, temos visto essas discussões em torno da "internação compulsória”: fala-se que as práticas institucionais não se darão como antes, que não se praticará mais a internação punitiva. Objetiva-se agora a cuidar e tratar. Médicos, psicólogos, assistentes sociais, etc. serão contratados para que um trabalho técnico seja realizado e por isso não predominará mais nosso contumaz desleixo institucional.

Muito bem, esses técnicos serão contratados para fazer o quê? Eles sabem o que fazer? Deram provas disso? Onde estão estas provas? Se elas existem, por que até hoje não se replicou simplesmente, sem tanto alarde, o que deram provas de que podiam fazer?

De nossa parte, acreditamos que se trata de recomendar a prudência, certo recolhimento e um pouco mais de modéstia, pois, de fato, sabemos pouco disso tudo e, por isso, antes de mais nada, é preciso investigar essa realidade acatando de algum modo sua densidade histórica e cultural.

Com efeito, no Brasil, o investimento no campo cultural, seja no extrato da saúde, da educação, da assistência social ou qualquer outro, é muito baixo, sobretudo quando o que está em jogo são as dinâmicas culturais das quais esses extratos do Estado participam e agenciam. Até porque esse investimento não se mede apenas pelo quantitativo dos aportes financeiros.

Aqui mesmo, em nossas universidades públicas, de que forma se preparam os alunos, futuros técnicos dos serviços de saúde, a enfrentarem essas situações? Disciplinas, estágios, especializações, pós-graduações, tudo isso se debruça sobre a questão, para fazer face a ela na extensão que ela exige? Há uma configuração do trabalho efetivamente proposta para enfrenta-la? Algo como uma política abrangente coordenando vários planos de intervenção, com técnicos e funcionários motivados, capacitados e pagos corretamente?

É recente, por exemplo, esse convite à saúde para lidar com a juventude em vias de delinquir e candidata a viver nos limites do sistema carcerário quando adulta. Tivemos que esperar essa juventude se envolver seriamente com as drogas e seu tráfico, esse consumo adquirir a feição de um costume extensamente praticado nas comunidades, e seu comércio adquirir características institucionais do tipo empresarial para, isto tendo já avançado muito, começarmos a propor tratamentos específicos para essa situação. Apesar de algum reconhecimento da particularidade dessas conjunturas culturais, a situação ainda é muito confusa, as propostas são, muitas delas, controvertidas, com resultados muito obscuros e entre elas frequentemente contraditórias; falta sobretudo coordenação das iniciativas em seu conjunto. 


\section{A CLÍNICA, AS CONDIÇÕES HISTÓRICAS E CULTURAIS}

Consideremos alguns pontos em que nossa sensibilidade de praticantes da psicanálise nos deteve. A família, sobretudo a situação do parentesco, e a organização da autoridade. Bem poderíamos começar com a pergunta: o que se pode dizer da família e do parentesco nesses casos (LÉVI-STRAUSS, 1983). Agora temos essa iniciativa importante de o governo federal buscar fortalecer a Atenção Básica através de uma abordagem da família - "Saúde da Família" é sua designação. Ora, o que se entende por família (FONSECA, 2005)?

É muito comum, nessas conjunturas, a existência de grupos primários organizados em torno da autoridade materna, cujos filhos provêm de vários companheiros. O pai, muitas vezes decaído, quando não desconhecido, assassinado ou preso. Trata-se de organizações que tendem a uma espécie de matriarcado (a distinguir de uma organização do parentesco cuja linhagem é matrilinear, o matriarcado é uma organização na qual a autoridade está centrada na figura materna). Situadas muitas vezes à margem de uma inserção consistente no sistema produtivo (integrantes com pouca ou nenhuma capacitação e entrada no mundo do trabalho formal) - e praticando uma "economia do dom" em destroços.

Essa situação é histórica, pois, com efeito, uma das obras operadas pela colonização com os escravos foi o apagamento de suas marcas étnicas juntamente com a não formulação de qualquer alternativa para eles estarem dentro da cultura, propriamente, que não a de segregados. É importante inclusive ressaltar a esse respeito que é recente, em nosso contexto cultural, uma espécie de marcação étnica pela via real da cor, pois efetivamente nunca foi tolerado pelas elites que as classes trabalhadoras se organizassem a partir das marcas simbólicas que diziam respeito às suas origens.

Assim, ao dizer que seu pai é "corno" - e efetivamente encontrar um pai como suporte de tal fala, sem possibilidade de produzir para isso qualquer relativização - o sujeito apenas enuncia o lugar do pai nessa conjuntura cultural ao longo das gerações. Não é por outra razão que ele espanca sua namorada no ponto preciso em que esta o convoca a ser pai. Mais do que ser violento, ele apenas reproduz a figura degradada de pai para seu filho a vir, pois sua namorada terá de qualquer modo o filho e ele terá sido apenas mais um pai degradado, tão violento em seu espasmo viril quanto impotente para realizar sua função de relativizar a autoridade materna junto a seu filho. Este, por sua vez, terá de situar essa mãe que o protege da violência desse seu pai como o polo de autoridade, uma autoridade real, a orientá-lo na vida com todas as consequências daí advindas.

Finalmente, temos o modo como as instituições entram na vida dessas pessoas quando consideramos a dimensão subjetiva, do endereçamento aos semelhantes em função da posição no discurso. Charles Melman (1983/2000), seguindo a via de Lacan (1950/1966/1998) nos lembra que a constituição do sujeito implica 
necessariamente o laço social enquanto endereçamento aos outros e ao Outro. No caso da neurose, nossa normalidade, as estruturais sociais sendo simbólicas, garantiriam, a partir desse fato, a possibilidade de o neurótico vir a praticar condutas reais - o que justamente configura a grande questão neurótica a respeito de ações e atos. No caso da delinquência, ocorreria o inverso: as estruturas sociais teriam incidência (apenas) real e as condutas do delinquente visariam instituir o simbólico a partir do qual o sujeito poderia se situar — como se buscasse, pela delinquência, constituir-se, encontrar um lugar como sujeito.

Isso apresenta muitas ressonâncias quando se consideram as origens históricas de nosso lumpemproletariado. Mas o que há a ressaltar aí é, sobretudo, as respostas das instituições como estruturas sociais reais. Trata-se de um exercício de autoridade presencial, em que a autoridade não é delegada e aquele que a exerce não é, de modo algum, um representante, como seria o caso de uma autoridade constituída simbolicamente. É uma autoridade que se apoia na força de sua presença e se exerce diretamente a partir desta, sem mediação.

Vimos que a primeira figura a se colocar desse modo, ainda no grupo primário, é a mãe. Nada emerge no horizonte desses sujeitos que possa marcar o valor da palavra enquanto possibilidade de pacto - é sempre o real que é indicado, “meu pai é corno": o pai enquanto representante é depreciado e seu pai "mesmo", o pai real é o vizinho; e ambos não valem grande coisa.

A seguir, as instituições o tomam como objeto, o sujeito é transferido de um lugar a outro segundo os mais diversos desígnios e raras vezes é considerada a questão de seus vínculos, do que tem ou não a dizer — ele é muito mais objeto de um poder que o sabe tão completamente quanto o manipula sem assinalar-lhe um lugar a partir do qual possa ter algo a dizer sobre seu destino. É nessa via que ele assume a delinquência como sua assinatura. Mas isso é sem saída, pois quanto mais a idade avança, mais suas atuações delinquentes justificam a ação desse poder-saber sobre ele como exercício de uma autoridade real. O próprio tráfico, com sua lei do cão, funciona do mesmo modo. A coisa culmina nesse ponto, por ele mesmo formulado — o CCC — já aos 18 anos, ou levará um tiro e restará em uma cadeira de rodas, ou irá para a prisão ou será morto. Ou seja, o sujeito é "lúcido" quanto ao fato de que seu destino se trava no real, pouco a esperar de uma possibilidade de se fazer representar por sua palavra, mesmo que sua conduta delinquente vise isto.

\section{PARA CONCLUIR: A GRAVIDADE DA SITUAÇÃO E O TRATAMENTO POSSÍVEL}

Por fim, gostaríamos de lhes propor "medir” a gravidade da situação.

Esse sujeito, ao chegar ao Caps, ou seja, no momento em que entra em sua vida uma instituição da Saúde, configura-se uma situação nova tanto para ele 
quanto para a própria equipe. Vejamos como: ele vem “ensaiado”, já sabe como se conduzir nas instituições, provocá-las. É surpreendido pela psicóloga que o atende, não tanto por sua habilidade técnica propriamente, mas pelo fato de ela ter se permitido responder-lhe a partir de como foi afetada por sua fala. Em certo ponto, quando ele comenta sobre os espancamentos em sua namorada, a psicóloga diz-lhe, transtornada, que isso não é possível, não pode ser assim. A partir daí, ele passa a falar de outro modo, passa a falar mais "sério". Chega a pedir ajuda na forma de internação - o que é feito. Transcorrem algumas peripécias, fugas, roubos, mas curiosamente é à psicóloga que ele retorna.

Não se espera que, ao nos oferecermos para receber essas pessoas, elas abandonem o campo de atuação no qual se exercem; junto com elas vem isso que é delas, da condição delas; sobretudo esse franqueamento para a ação com todo tipo de consequência que isso traz.

Em resumo, não se troca essa modalidade de se exercer pela atuação — se é que isso é possível - , pela palavra, subitamente. Por exemplo, em uma ocasião, um jovem vem ao Caps após roubar o celular de um vizinho e este, a seguir, lá aparece acompanhado da mãe do rapaz para forçá-lo a restituir um telefone que roubara. Ele foge. Sobrevêm as ameaças do vizinho, "quadro" do tráfico: "é fácil matá-lo, nós [o tráfico] sabemos que ele está vindo ao Caps, basta um tiro... só não fizemos isso porque é aqui um lugar de tratamento...”. A equipe, muito corajosa, porquanto não desiste dele e se coloca em posição de acolhê-lo, vai pouco a pouco observando, não sem surpresa de todos, uma modificação de seu comportamento, e no teor do que diz: menos atuação e uma maior tematização através de sua fala de suas questões com sua psicóloga. Mas as estruturas sociais enquanto reais se impõem e o provocam. Ele sabe a regra do jogo, vai se realizando então algo que vem desde sempre em sua fala: dos três Cs, o destino que se anuncia no presente para ele é a cadeia, uma resposta da justiça. Inclusive é onde ele situa uma dívida, um desfecho no qual se verifica não a queda definitiva de seu corpo, como seria no caso do assassinato ou da invalidez, mas um horizonte nem por isso menos sinistro — a prisão — de restituição. Um pagamento também real, mas que lhe dá alguma chance de preservar a vida.

No entanto, para nós, uma questão insiste: que ele seja preso é um desfecho jurídico, mas o que dizer de seu tratamento? Ele coincidirá com o exílio absoluto da vida coletiva e pública que é representado por nossas prisões? E seus filhos? Sua namorada está grávida de gêmeos, seus filhos terão de, fatalmente, percorrer esse mesmo trajeto que sua família percorre já há três gerações? Não é demais destacar, nessa conjuntura tão difícil, a importância do prático clínico informado pela psicanálise, para apreender aspectos cruciais da trajetória dessas pessoas e, sobretudo, para sustentar o deslocamento que incide na formulação 
mesma da problemática na medida em que se dá lugar à palavra, ao discurso, e enfim, ao sujeito.

Na tomada da palavra em que o sujeito se realiza pode residir, num átimo, uma chance de subversão da objetalização ordinária agenciada pela conjuntura institucional. Bastará isso para produzir algum deslocamento efetivo que realize o sujeito e marque a estrutura? Não se pode saber de antemão. A questão, como se disse acima, é real. E constatar essa condição impede qualquer afirmação de um decálogo moral. Pelo contrário, para aqueles que estão comprometidos com a psicanálise isto acarreta as exigências relativas àquilo que Lacan (1964/1985) nomeou como "presença do analista”: uma intervenção que se que se faz em ato e que requer ser sustentada, a cada vez, por alguém que pague, com seu corpo, suas palavras, e em ruptura com as pequenas estabilidades que organizam a vida de cada um, o preço da aposta da psicanálise.

Recebido em 18/2/2012. Aprovado em 11/3/2014.

\section{REFERÊNCIAS}

AMADO, J. (1937/1972) Capitães de areia. Rio de Janeiro: Martins.

FONSECA, C. (2005) Concepções de família e práticas de intervenção: Uma contribuição antropológica. Revista Saúde e Sociedade, v.14, n. 2. Disponível em http://www.scielo.br/scielo.php?script=sci_ arttext\&pid $=$ S0104-12902005000200006\&lang $=$ pt. Acesso em $12 / 12 / 2013$

LACAN, J. (1950/1966/1998) “Introdução teórica às funções da psicanálise em criminologia”. In: Escritos. Rio de Janeiro: Zahar.

. (1964/1985) O Seminário Livro 11: Os quatro conceitos fundamentais da psicanálise. Rio de Janeiro: Jorge Zahar Editor.

LÉVI-STRAUSS, C. (1983) Famille, mariage, parenté. In: Le Regard Éloigné. Paris: Plon.

MELMAN, C. (1983/2000) Observações sobre a delinquência. In: Alcoolismo, delinquência, toxicomania. São Paulo: Escuta.

PONTE-PRETA, S. (1966/1996) Febeapá1: Festival de Besteiras que Assola o País. Rio de Janeiro: Civilização Brasileira.

(1967/1976) Febeapá2: Festival de Besteiras que Assola o Pais. Rio de Janeiro: Civilização Brasileira.

Francisco Leonel F. Fernandes

francisco.lf@mac.com 
